\title{
Design and Development of a Digital Weight Management Intervention (ToDAy): Qualitative Study
}

Charlene L Shoneye ${ }^{1}$, BSc, Grad Dip, PGD, MSc; Barbara Mullan², BA (Hons), MA, PhD; Andrea Begley ${ }^{1}$, BSc, Grad Dip, MPH, DrPH; Christina M Pollard ${ }^{1,3}$, BSc, Grad Dip, MPH, PhD; Jonine Jancey ${ }^{4}$, BSc, PhD; Deborah A Kerr ${ }^{1}$, BSc, Grad Dip, MSc, PhD

\footnotetext{
${ }^{1}$ School of Public Health, Curtin University, Perth, Western Australia, Australia

${ }^{2}$ Health Psychology \& Behavioural Medicine Research Group, School of Psychology, Curtin University, Perth, Western Australia, Australia

${ }^{3}$ East Metropolitan Health Service, Perth, Western Australia, Australia

${ }^{4}$ Collaboration for Evidence Research \& Impact in Public Health, School of Public Health, Curtin University, Perth, Western Australia, Australia
}

\section{Corresponding Author:}

Deborah A Kerr, BSc, Grad Dip, MSc, PhD

School of Public Health

Curtin University

GPO Box U1987

Perth, Western Australia

Australia

Phone: 6161892664122

Email: D.Kerr@curtin.edu.au

\section{Abstract}

Background: The Tailored Diet and Activity (ToDAy) study aims to build on the campaign by adding a digital intervention with the potential to provide wide-reaching, cost-effective weight management support.

Objective: The ToDAy study aims to build a tailored intervention using mobile technology to improve diet and physical activity behaviours in adults with overweight and obesity. The main objectives were to identify behavior change techniques for diet and physical activity (PA) change for weight loss and explore preferences for digital intervention features that would be effective in changing diet and PA behaviors.

Methods: This qualitative study uses the principles of a person-based approach to intervention development; the behavioral intervention technology framework; and the capability, opportunity, motivation, and behavior (COM-B) framework. Focus groups and telephone interviews were conducted with 56 adults in Western Australia. Open-ended questions and example intervention features were used to explore the usability and acceptability of the self-monitoring tools, knowledge about effective weight-loss strategies, and acceptability of tailored feedback. Findings from the focus groups and interviews were analyzed using thematic analysis.

Results: Qualitative findings revealed an awareness of key public health messages but a lack of confidence in how to perform these behaviors to help manage their weight. A total of 4 major themes were identified and mapped to the domains of the COM-B framework: (1) misinformation, (2) environmental support, (3) social norms, and (4) confidence.

Conclusions: This study explores users' capability, opportunity, and motivation to perform the target behaviors for weight loss. The findings suggested that a digital weight management intervention using a mobile food record and activity trackers to inform tailored feedback may be acceptable and feasible. Participants expressed a preference for simple expert advice, digital self-monitoring tools, and visual feedback.

International Registered Report Identifier (IRRID)： RR2-10.2196/12782

(JMIR Mhealth Uhealth 2020;8(9):e17919) doi: $\underline{10.2196 / 17919}$

\section{KEYWORDS}

obesity; diet; physical activity; sedentary behavior; digital behavioral interventions; health behavior; wearable activity monitor; health; mobile food record; clinical trial; focus group; qualitative research; mobile phone 


\section{Introduction}

\section{Background}

Excess weight has overtaken smoking as the leading cause of noncommunicable disease in Australia, with 7 out of 10 males and almost 6 out of 10 females living with overweight or obesity [1]. The causes of this are multifaceted [2] but, at a personal level, poor diet and inactivity are major contributors. In Australia, excessive intake of alcohol, sugar-sweetened beverages (SSBs), and discretionary foods (foods considered to be of little nutritional value; often high in saturated fats, added sugar, and salt; and alcohol or junk foods) are observed across all age groups [3]. Mass media campaigns, targeting healthy weight, positively influence knowledge and awareness with modest impacts on behavior [4-7]. LiveLighter is a Western Australian public health education and social marketing campaign that aims to encourage people to eat well, be physically active, and maintain a healthy weight. The campaign engages with the community through paid and unpaid social media, web-based and printed resources, and retailers. Campaign messages include graphic images of toxic fat, followed by messages with single actions to reduce the risk of weight gain, for example, by avoiding SSBs or junk food [8]. The advertisements also direct people to a campaign website where there is an option to enroll on the web to access a meal planner, recipes, and weight-monitoring tools and to receive update emails. The Tailored Diet and Activity (ToDAy) study aims to build a digital intervention that provides individualized tailored feedback on dietary and activity behaviors.

In Australia, the evaluation of the LiveLighter mass media campaign targeting sugary drinks indicates a high campaign recall and modest reductions in SSBs [4,9-11].

However, $>60 \%$ of adults in Australia do not usually consume SSBs and may disregard the campaign, even if they stand to benefit from some of the other elements. A growing body of evidence supports the notion that information is best tailored specifically to the unique characteristics and behaviors of an individual [12-17], with significant effects reported for nutrition and PA.

Australian clinical guidelines for weight management recommend a multidisciplinary team of health professionals using specific behavior change techniques (BCTs) applied for a minimum of 12 months [18]. High attrition rates, low availability of trained health professionals, and logistical issues are among the commonly reported barriers to putting this in practice [19]. Digital interventions that combine clinical and tailored content with the reach of mass media could be a cost-effective solution [20].

\section{Developing Digital Interventions}

The process of developing a digital intervention requires integrating the behavior change theory with intervention features that are engaging and acceptable to the target group. Evidence from other digital behaviour change interventions suggest an iterative and multidisciplinary approach that includes a qualitative investigation with the end user before implementation $[14,21,22]$. Specifically, the person-centered approach recommends using qualitative research to explore and test intervention features with the target group [23]. This allows researchers to adapt the intervention features based on the preferences and needs of the user. A BCT is the active ingredient or intervention component that changes the desired behavior [24]. For example, BCT 2.3 is self-monitoring of behavior, the most commonly used BCT in effective diet and PA interventions [25]. Evidence suggests that self-monitoring works through behavioral regulation; for example, dietary self-monitoring increases the awareness of food choice, portion sizes, and improving diet quality [25,26,27]. Exploring digital interventions for weight management that combine the reach of mass media campaigns with tailored and clinical support could be a cost-effective and practical approach.

Focus groups and interviews are commonly used to generate discussion and explore participants' experiences as well as their needs, knowledge, and preferences [28,29]. However, weight stigma inhibits participation and the willingness to share personal beliefs $[29,30]$. One strategy to address this is to show participants hypothetical scenarios and ask them to provide advice for weight loss [28,29]. Another strategy to address this is to use hypothetical scenarios where information about a person's PA levels or images of their meals is shown and participants are asked to provide advice on weight loss. To date, this unique approach has not been undertaken in this population.

Although men are more likely to be living with excess weight and experience health-related illnesses, they are less likely to participate in lifestyle interventions, making up only about $20 \%$ of participants [31]. Studies aiming to reduce this gender imbalance have reported that self-monitoring technology, including mobile apps and wearable devices, are great incentives to engage men in weight management $[32,33]$. To date, few weight management studies have included the views and experiences of men aged $>25$ years [34]. This study aims to address this shortcoming by purposely sampling an equal number of male and female participants.

This study aims to describe the qualitative study and iterative process used to develop ToDAy, a digital, tailored, weight management intervention. A full description of the aims of the 12-month intervention and the protocol has been published elsewhere [35]. The objectives of this study were to (1) identify BCTs for dietary and PA changes concerning weight loss and (2) explore preferences for digital intervention features that would be effective in changing diet and PA behaviors.

\section{Methods}

\section{Study Design}

The methodological approach used in this research was a general inductive, qualitative approach [36]. The Consolidated Criteria for Reporting Qualitative Research for interviews and focus groups were used to ensure rigor in the presentation of the findings [37]. ToDAy will incorporate learnings from an earlier trial where a mobile food recording app (mFR) was successfully used to assess dietary intake and provide tailored feedback on fruit, vegetable, and junk food intake in young adults [38,39]. 
Open-ended questions and example intervention features were used to explore the usability and acceptability of the self-monitoring tools, knowledge about effective weight loss strategies, and acceptability of the tailored feedback.

We used an iterative intervention development process applying the behavioral intervention technology (BIT) theory [40,41] and the person-based approach [23]. An overview of the 3 stages of intervention development is provided below.

\section{Stage 1}

To derive the measurable and clinically significant behavioral changes that could be expected from the intervention, we reviewed the recent literature and evidence-based guidelines from the Australian scientific authoritative bodies. These included the National Health and Medical Research Council's clinical guidelines for weight management [18], the Australian Dietary Guidelines [42], and the Australian government's PA guidelines [43]. We determined the clinically significant target behaviors for the intervention as follows:

\section{Dietary:}

1. Daily dietary energy reduction of $2000 \mathrm{~kJ}$.

2. Avoiding or limiting energy-dense nutrient-poor (EDNP) foods, SSBs, and alcohol.

3. Eating less at meals or additional snacks (except fruits and vegetables).

4. Eating less often $[18,42]$.

PA:

1. Daily step count $\geq 10,000$.

2. $\geq 30$ active minutes (spent in moderate-to-vigorous PA).

3. $\geq 250$ steps per hour [43].

Weight loss:

1. $5 \%$ reduction in body weight [18].

Target behaviors: The ToDAy study investigated whether a digital, tailored intervention can improve diet and PA behaviors in adults with overweight or obesity. A total of 16 health professionals with expertise in dietetics, PA, health promotion, and community engagement were consulted in a series of 5 workshops and meetings to explore the target behaviors needed to achieve the clinical aims and where, when, why, and who they occur with [45].

\section{Stage 2}

The research team developed a user-friendly script for the focus groups and interviews with a male and female consumer representative [46]. Focus groups and interviews were conducted with volunteers to explore the acceptability of the selected BCTs and their preferences for digital intervention features. The findings of these focus groups are presented in this paper.

\section{Stage 3}

Target behaviors were mapped to possible intervention features by the research team with reference to previous research $[47,48]$ and following guidelines for developing complex behavior change interventions [49,50]. Focus groups and interviews were followed by a review of intervention features by the research team. This was repeated in a cyclical manner to allow continued user involvement in the design and development of the final intervention.

Approval for the study was granted by the Curtin Human Research Ethics Committee (HR E2016-0271). All participants agreed to an audio recording of their focus group or interview and provided informed consent. All data were collected between October and November 2016 in Western Australia (spring).

\section{Theoretical Frameworks}

Several guidelines exist for the development and assessment of evidence-based apps and web-based interventions [50-52]. As this intervention uses a combination of digital tools, that is, an mFR, a wearable PA tracker, text messages, and emails, a combination of theoretical approaches and guidelines was drawn upon. The BIT framework was used to identify the technology and procedures for delivering clinical aims and BCTs (objective 2) [40]. The models help to identify clinical aims and link these with suitable intervention features for testing with the user (Table 1).

The capability, opportunity, motivation, and behavior (COM-B) model was then used to guide the selection of intervention features and strategies such as self-monitoring, goal setting, motivation enhancement, and feedback on performance (objective 1) [45]. The COM-B model aims to specify behavioral targets and support psychological theories when developing interventions [45]. The COM-B model states that 3 factors are needed to change behavior: capability $(\mathrm{C})$, opportunity $(\mathrm{O})$, and motivation (M). According to this model, performing a behavior (B) first requires individuals to be capable (C) or have physical and mental abilities (eg, nutrition knowledge, cooking skills). Following this is opportunity, which includes both practical and social aspects (eg, access to healthy food that is culturally acceptable and within social norms). Finally, motivation includes automatic drivers like habits as well as beliefs, plans, and impulses. Table 1 illustrates the steps in the development process - why, how, what, and where? The what includes the BCT and associated taxonomy number to identify each BCT from the Behavior Change Technique Taxonomy v1 (BCTTv1) [53]. 
Table 1. Relationship among clinical aims, behavior change techniques, and intervention features (technology).

\begin{tabular}{|c|c|c|c|}
\hline $\begin{array}{l}\text { Why? Clinical aim or } \\
\text { population health focus }\end{array}$ & How? Action & What: behavior change techniques ${ }^{\mathrm{a}}[53]$ & $\begin{array}{l}\text { Where: potential intervention fea- } \\
\text { tures tested in qualitative research }\end{array}$ \\
\hline Reduce BMI by $5 \%$ [18] & $\begin{array}{l}\text { Reduce energy intake by } \\
2000 \mathrm{~kJ} \text { per day and in- } \\
\text { crease } \mathrm{PA}^{\mathrm{b}}(10,000 \text { steps })\end{array}$ & $\begin{array}{l}\text { Provide information on the consequences }(5.1) \text {, goal setting } \\
\text { (behavior and outcome; } 1.1,1.3) \text {, and review of behavior } \\
\text { goals }(1.5)\end{array}$ & $\begin{array}{l}\text { Tailored feedback, weight tracker, } \\
\text { PA tracker }\end{array}$ \\
\hline $\begin{array}{l}\text { Reduce EDNP }{ }^{\mathrm{c}} \text { foods } \\
\text { [42] }\end{array}$ & $\begin{array}{l}\text { Increase awareness of } \\
\text { EDNP intake }\end{array}$ & $\begin{array}{l}\text { Goal setting (behavior and outcome; } 1.1,1.3) \text {, review of } \\
\text { behavior goals }(1.5) \text {, provide feedback on behavior }(2.2) \text {, } \\
\text { and social comparison }(6.2)\end{array}$ & $\begin{array}{l}\text { Mobile food record; tailored feed- } \\
\text { back and tailored education; app } \\
\text { alerts, eg, Have you had any } \\
\text { snacks today? }\end{array}$ \\
\hline Reduce SSBs ${ }^{\mathrm{d}}$ [42] & $\begin{array}{l}\text { Increase awareness of } \\
\text { energy in SSBs and in- } \\
\text { take }\end{array}$ & $\begin{array}{l}\text { Self-monitoring of behavior }(2.3) \text {, goal setting (1.1), barrier } \\
\text { identification, provide feedback on behavior }(2.2) \text {, and so- } \\
\text { cial comparison }(6.2)\end{array}$ & $\begin{array}{l}\text { Mobile food record tailored feed- } \\
\text { back and tailored education }\end{array}$ \\
\hline $\begin{array}{l}\text { Increase fruit and veg- } \\
\text { etable consumption [42] }\end{array}$ & $\begin{array}{l}\text { Increase awareness of } \\
\text { current intake }\end{array}$ & $\begin{array}{l}\text { Self-monitoring of behavior ( } 2.3) \text {, discrepancy between } \\
\text { current behavior and recommendations }(1.6) \text {, action plan- } \\
\text { ning (1.4), problem solving (1.2), and instruction on how } \\
\text { to perform behavior ( } 4.1)\end{array}$ & $\begin{array}{l}\text { Mobile food record tailored feed- } \\
\text { back and tailored education }\end{array}$ \\
\hline $\begin{array}{l}\text { Reduce alcohol intake } \\
\text { [54] }\end{array}$ & $\begin{array}{l}\text { Increase awareness of } \\
\text { current intake }\end{array}$ & $\begin{array}{l}\text { Information on health consequences }(5.1) \text {, motivational } \\
\text { interviewing, and self-monitoring of behavior }(2.3)\end{array}$ & $\begin{array}{l}\text { App alerts, eg, How confident are } \\
\text { you about having an alcohol-free } \\
\text { dinner tomorrow night? }\end{array}$ \\
\hline
\end{tabular}

${ }^{\mathrm{a}}$ Behavior change technique and associated taxonomy from the Behavior Change Technique Taxonomy v1 (BCTTv1) [53].

${ }^{\mathrm{b}} \mathrm{PA}$ : physical activity.

${ }^{\mathrm{c}}$ EDNP: energy-dense nutrient-poor.

${ }^{\mathrm{d}}$ SSBs: sugar-sweetened beverages.

\section{Recruitment}

Recruitment was specific and purposeful [55], aiming for a similar number of males and females and including people with overweight or obesity who had some experience of the LiveLighter campaign [8]. A single recruitment email was sent to 20,000 adults who had registered with the LiveLighter website in October 2016. The email was sent to the entire mailing list of LiveLighter members, inviting them to take part in the study by clicking on a study web link where participants completed web-based consent and screening. The website was closed after 2 days as 245 respondents had completed the screening questionnaire. The respondents who met the criteria were sent further details on how to participate in a focus group or interview. There were 145 eligible participants, who were $>18$ years and had a BMI over $25 \mathrm{~kg} / \mathrm{m}^{2}$. The time, date, and location of the focus groups were sent to the eligible participants to allow them to choose the most convenient time. As $85 \%$ of the sample were women, additional recruitment strategies were employed to encourage male participants, such as offering a one-to-one telephone call and men-only focus groups. When these additional approaches were not successful, a workplace with a high proportion of males was contacted and an onsite focus group was arranged, with 14 men in attendance.

\section{Script Development}

The topics covered in the focus groups and interviews were informed by the literature as important features for weight loss interventions and included self-monitoring of diet and PA behavior, feedback on performance, reducing intake of discretionary food drink and alcohol, reducing sedentary time, and increasing steps per day. The script was pilot tested with researchers at Curtin University and 2 consumer representatives where feedback on clarity was provided. Focus groups were conducted in community settings, community centers, place of work, and Cancer Council WA meeting rooms. For each session, the script was accompanied by a visual presentation of example images and draft intervention features. Multimedia Appendix 1 contains the basic script used for focus groups and interviews.

A semistructured focus group and interview guide with open-ended questions were developed, which allowed an iterative, person-centered data collection process $[23,56]$. As a result, a variation of the script was used in each session. For example, "the last group suggested the dietary feedback include their food images so they can see where the junk food came from. What do you think of this idea? Have a look at this example. Is there anything you would change?"

\section{User Preferences}

Preferences for digital intervention features explored willingness to use the digital self-monitoring tools as well as the frequency and duration of self-monitoring. Preferences for digital feedback explored the format, frequency, length, and content of the tailored diet and PA feedback. With regard to digital content to address the target behaviors, participants were asked to suggest helpful advice and potential barriers to changes for a particular behavior, for example, "What feedback could we send to help this person lose weight?" and "What sort of things do you think might get in the way?"

\section{Self-Monitoring Tools}

The usability and acceptability of the self-monitoring tools were explored. First, participants were given an opportunity to use the mFR [57-59]. This image-based dietary assessment tool uses the integrated camera in a smartphone to capture images of food and beverages. The images are automatically uploaded 
to a server for dietary analysis by the research dietitian and used to inform the tailored dietary feedback. The usability and acceptability of the mFR to monitor dietary intake and a wearable device to monitor PA were explored.

\section{Behavior Change Beliefs Regarding Weight Loss}

Participants were given examples of a scenario and asked to provide advice to a hypothetical person to help them lose weight.
For example, "people in this study will use an app on their phone to take pictures of their food and drink. Imagine we received this picture from a man wanting to lose weight, what advice should we give him?" (Figure 1). Participants, who were interviewed on the phone, were emailed this information and the images in advance.

Figure 1. Example of image shown to participants where they were asked what advice they would give this person to help them lose weight.

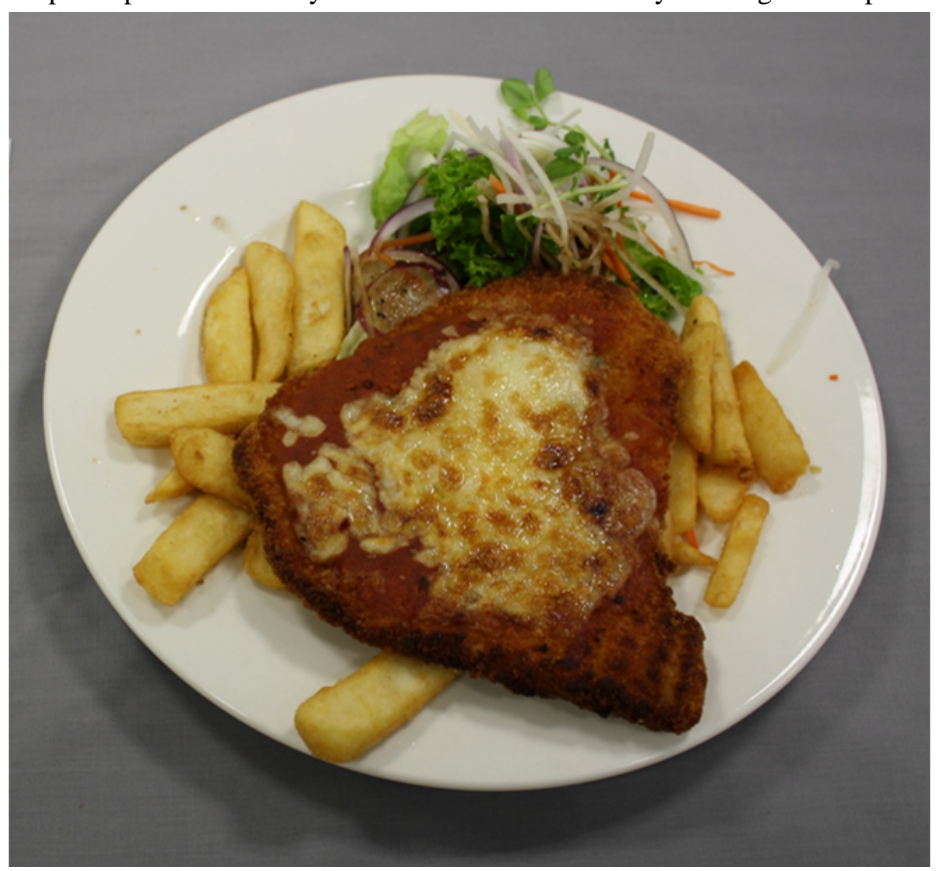

\section{Acceptability of the Feedback Messages}

The acceptability of feedback messages, including the length, content, and tone, was explored. Example feedback on diet and PA behavior were shown to participants with questions to explore their understanding and acceptability of the feedback. For example, Figure 2 shows an example of PA feedback where participants were asked to "imagine we sent a person this feedback. How do think they might feel about receiving this feedback? Is there any other information you would add?"

Figure 2. Example of physical activity feedback shown to participants for their comment.

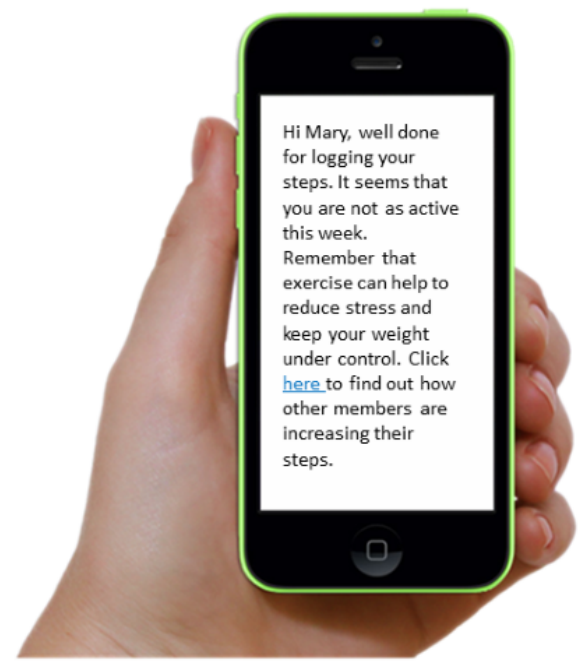

After each focus group, new ideas were discussed with the research team (qualitative researcher, dietitian, exercise physiologist, and health psychologist) and potential digital intervention features were developed. The script was adapted after each session using an iterative process to incorporate participant ideas and feedback, which were then explored in the subsequent sessions. Figure 3 provides an example of how intervention features evolved using feedback from participants. 
Figure 3. Example images showing how new ideas on how to provide dietary feedback were incorporated using an iterative process based on feedback from the previous focus group and interviews.

\section{Researcher question $\rightarrow$ Participant feedback 1}

"What do you think about this feedback on junk food?"

\section{"Include their images in the feedback"}

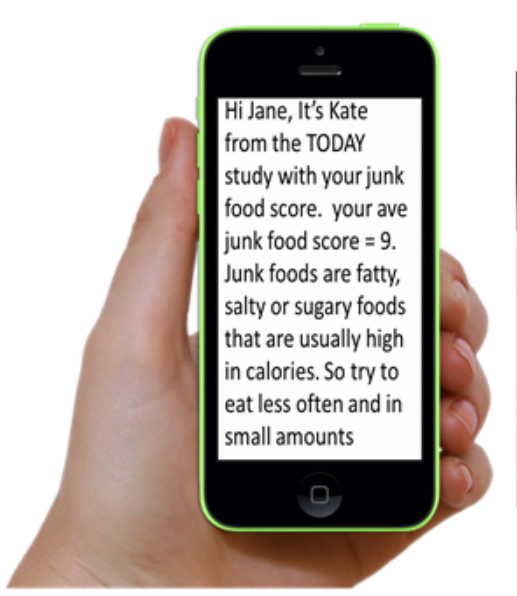

\section{Data Collection}

All interviews were conducted over telephone by author 1 , a dietitian (CS; female) who has qualitative research experience [60], with guidance from $\mathrm{AB}$, an established qualitative researcher [61,62]. Participants in the interview completed a consent form and a demographics questionnaire on the web. The focus group participants completed a consent form and a demographic questionnaire on arrival. $\mathrm{JH}$ facilitated the male-only group, with CS as a cofacilitator. CS facilitated all other groups, with 1 assistant moderator. Before the interviews and focus groups, participants had no relationship with the researchers and knew the study was about helping to develop a digital weight management intervention.

All focus groups and interviews started with an overview of the proposed ToDAy intervention, where participants monitor their PA with a wearable tracker and record their food and beverage intake with the mFR app. This information was used to provide feedback to help them lose weight. The first activity was a chance to employ the mFR used to capture images of food and beverage intake $[57,58]$. The facilitator demonstrated how to use the app to take pictures of plastic food models. Participants were then given an opportunity to use the mFR on a mobile device. This exercise served as an icebreaker as well as capturing the questions and comments of participants using the app. This was followed by open-ended questions to start the discussion. Focus groups and interviews lasted between 34 and 78 min and were conducted until reaching a saturation of ideas. At the end of each focus group, the facilitator summarized the main ideas or themes that participants had raised in that group and gained agreement from participants.

\section{Data Analysis}

All audio recordings were professionally transcribed verbatim and reviewed for accuracy by the first author and managed in NVivo. As this study used scripts that evolved between groups, the analysis used a thematic analysis to analyze and code data through the lens of the COM-B model [49]. Qualitative data were analyzed in 3 stages. Following the process of thematic analysis, first was familiarization through reading each transcript, highlighting key points, and discussing the findings with the cofacilitators [63]. The first author led the analysis and developed themes aligning with capability, opportunity, and motivation. The cofacilitators for the focus groups then independently reviewed the scripts. Finally, any discrepancies were reviewed and discussed by the first author. The quotes were then aligned to the final themes [64].

\section{Results}

\section{Participant Characteristics}

Table 2 provides an overview of the characteristics of the participants. A total of 56 adults (32 female and 24 male) from Western Australia participated in 6 telephone interviews and 6 focus groups (average of 5 per group). Of these, over one-third had a BMI $>30$. Half were employed full time (52\%), and most were aged between 25 and 40 years $(61 \%)$. All participants owned a smartphone (iPhone or Android) and had some experience using apps.

Feedback from focus groups and interviews provided important insights into the acceptability and comprehension of tailored feedback messages. For example, feedback suggesting healthier alternatives to junk food was rejected as these options may not be available and could not be tailored to the individual's preferences. 
Table 2. Characteristics of interview participants $(\mathrm{N}=56)$.

\begin{tabular}{|c|c|}
\hline Characteristics & Values, $\mathrm{n}(\%)$ \\
\hline \multicolumn{2}{|l|}{ Age (years) } \\
\hline $25-40$ & $34(61)$ \\
\hline $41-65$ & $17(30)$ \\
\hline$>65$ & $5(9)$ \\
\hline \multicolumn{2}{|l|}{ Gender } \\
\hline Male & $24(43)$ \\
\hline Female & $32(57)$ \\
\hline \multicolumn{2}{|l|}{ BMI $\left(\mathrm{kg} / \mathrm{m}^{2}\right)$} \\
\hline$<25$ & $10(18)$ \\
\hline $25-30$ & $23(41)$ \\
\hline$>30$ & $23(41)$ \\
\hline \multicolumn{2}{|l|}{ Ethnicity } \\
\hline Australian & $47(84)$ \\
\hline Indigenous Australian & $5(10)$ \\
\hline Asian & $4(7)$ \\
\hline \multicolumn{2}{|l|}{ Employment status } \\
\hline Employed full time or part time & $39(70)$ \\
\hline Unemployed & $8(14)$ \\
\hline Retired & $9(16)$ \\
\hline \multicolumn{2}{|l|}{ Household income Aus \$ (US \$) } \\
\hline$<\$ 50,000(<\$ 35,695)$ & $21(38)$ \\
\hline$\$ 50,000-\$ 150,000(\$ 35,695-\$ 107,085)$ & $22(40)$ \\
\hline$>\$ 150,000(>\$ 107,085)$ & $13(22)$ \\
\hline
\end{tabular}

\section{Qualitative Analysis}

Emerging qualitative themes and subthemes were mapped to the COM-B domains. This helped to identify that participants needed support in all 3 areas of capability, opportunity, and motivation.

\section{Capability: Misinformation}

Capability refers to knowledge and skills related to behavior [45]. Participants' knowledge of weight loss behaviors was examined by asking them to provide dietary advice to a hypothetical client based on a picture of their food and drink. Responses were themed as misinformation when they provided inaccurate information or nutrition advice. The majority of the discussion focused on giving misinformation as dietary advice. This revealed their knowledge and beliefs about which behaviors are best for weight management. For instance, 2 main examples were discussed. First, potatoes were considered fattening and second, excess alcohol was not a major contributor to weight gain. There was a focus on individual food being responsible for weight gain rather than a holistic view of the total diet.

\section{Carbohydrates Cause Weight Gain}

Participants were shown an extra-large roast dinner with large meat portions, 3 small potatoes, 3 serves of vegetables, and 6 bottles of beers and asked, "What advice would you give this person to help them lose weight?" All groups commented on the potatoes, only later mentioning the large serve of meat and 6 bottles of beer:

$$
\begin{aligned}
& \text { It's not a healthy meal if it's got a potato. [Female, } \\
& \text { FG2] } \\
& \text { Cut down on the carbs, only } 2 \text { potatoes. [Male FG3] }
\end{aligned}
$$

\section{Alcohol Consumption Does Not Cause Weight Gain}

The discussion did eventually focus on reducing the 6 bottles of beer, but there were a number of misinformed views about alcohol situations where 6 beers would be $O K$. For example, if it was a low-carb beer, consumed with fresh lemon, watching football, consumed over the course of an afternoon, the participant has eaten well during the preceding week or has a physical job that would work off excess energy. Some participants were dismissive of the kilojoule content of alcoholic drinks but aware that alcohol may lead to choosing discretionary foods:

So the kebab or the burger is a lot more appealing after a few drinks than it may be if say, while sober. [Male, PI 1] 
It's not the beer itself that's the problem, it's the food you have with it. [Female, FG2]

\section{Opportunity: Environmental Support and Social Norms}

The opportunity component of COM-B relates to physical opportunities, such as the environment and availability as well as social opportunities, including social influences. Both emerged as important themes in the data.

\section{Lack of Environmental Support}

Environmental factors were discussed as the main barriers to avoiding junk food. One group, in particular, expressed frustration at the density of fast food outlets and the promotion of very low-cost meals that would appeal to children and those on a low income:

When I first came in 1982 there was hardly any fast food places. Now you've got 8 or 9 different ones all down the road from each other. Kids have got 2 dollars where are they going to go? For a $\$ 2$ burger. [Male, FG 5]

Participants expressed that the social marketing campaigns and interventions for individuals were futile without addressing the food environment:

...that goes back to the government again because the government has put no restrictions on how much fast food can be in local vicinities. If you look at where they are, it's not in the high-class areas it's in the low socio-economic suburbs. [Male, FG 5]

\section{Unhealthy Food Is Everywhere}

Many participants thought that most food options purchased outside the home were not healthy and the serving sizes were too large. Some mentioned added fat, sugar, and salt. Others noted that savory meals often come with chips and sweets are served with cream or ice cream:

When you buy food out... It all tends to be fattening. [Female, FG 2]

Most groups brought up opportunistic eating as a key facilitator of eating discretionary food. Events such as at sporting occasions, bake sales, and sausage sizzles were given as common examples:

You can't buy a healthier option at a sausage sizzle, they only have sausage, white bread, and sauce. [Male, FG 4]

\section{Social Norms}

There has been some discussion about the difficulty of social opportunities. Most participants agreed that the expectations of consuming junk food at social occasions were problematic. When eating out, both men and women agreed that it is not socially acceptable for men to ask for healthy options or modification to their order. Regarding swapping chips for vegetables, a man said:

It's not seen to be manly to be seen like, eating vegetables. [Male, FG 3]

If it comes with chips, I'll eat chips. [Male, FG 4]
When discussing ways to reduce alcohol consumption, participants suggested practical methods, such as alternate alcohol with sugar-free soft drinks or choosing a low-strength beer. However, there was an overwhelming consensus that these suggestions were unrealistic and not socially acceptable for men:

...might be difficult if you're down at the club or in the pub with the guys and then you really get the Mickey taken out of you [Male, FG4]

You could suggest having water for every other drink, but who is going to listen to that? [Male, FG 5]

\section{Motivation}

The main theme that emerged from the motivation domain of COM-B was confidence.

\section{Confidence}

Participants were uncertain about their knowledge or beliefs about food, PA, or weight management. Some of this was linked to the perception that the guidelines from professionals were always changing. There was a sense of complacency about the need to or the importance of achieving health recommendations:

What would have been recognized as a healthy meal years ago, these days it's not a healthy meal because it's got potato; carbs. [Male, PI 3]

\section{Already Doing Enough}

In relation to PA, most adults felt they were already active with daily activities, including looking after children, gardening, housework, and those in nonsedentary employment (eg, nurse, carpenter, and plumber). Motivation to engage in PA was limited by the belief that their lives were already active and busy:

\section{... A mother of 3, busy all day, being told to go for a 45-minute walk. They can't otherwise they would have done it. [Female FG 2]}

Concerning eating, most agreed that there was a place for junk foods, namely takeaways, confectionery, and desserts. Making healthy food choices was said to be important, especially for those with health problems like diabetes and high blood pressure. There was a variety of beliefs about how often people should make healthy food choices. Some used broad terms, such as sometimes or not too often. Others believed that healthy eating and being active were part of the working week and not applicable on the weekend:

I mean you can eat healthy but every now and again you can always have take away. But not every week or every day. If you know what I mean? [Female FG 1]

During the week it's structured. You've got, you know, time to get to work and your lunch break at work or whatever and then, you know, you come home and it's dinner time and then that's that. Then your weekends are your time to just flop. It's like a treat. Weekends are your time to relax and enjoy life I guess. [Female, PI 2] 


\section{Reality of Change}

When the group was shown potential feedback to address alcohol intake, there was general agreement that changing would be difficult or even impossible. Specifically, several people thought that any feedback to reduce alcohol intake would be futile:

You could tell him to stop at four beers, but by then he won't know what he's doing. [Male, FG 5]

\section{Ambivalence}

There was a conflict in the expectations of the interventions. Some felt that feedback should tell them the negative consequences of their poor health choices:

In three years at that rate, your liver is going to look like this. [Male, FG 5]

However, feeling judged or reprimanded was cited as a barrier to keeping people engaged and honest about self-reporting. Participants wanted a specific example of food they could swap rather than a general avoid this or chose a healthier option. At the same time, they said specific advice would be unrealistic:

\section{All well and good to suggest a healthy option but you can't get your chicken parmigiana grilled with a baked potato at my local, it comes deep-fried with chips. [Female, FG 3]}

These comments reflect the ambivalence about eating junk food outside the home; something they want help to avoid because it is expensive, is unhealthy, and leads to overeating but something they do because it is convenient and enjoyable.

\section{Functions and Features of the Intervention}

Results from the focus groups and interviews informed the selection of user preferences, intervention functions, and acceptability of the intervention. Table 3 shows the results on the acceptability of digital tools proposed for self-monitoring diet and PA. Participants found the mFR app to be intuitive and convenient in comparison with other digital tools or paper-based methods. All participants shared experiences of using a pedometer and saw the option for a wearable PA tracker as an incentive to join the study. Feedback on the clinical aims highlighted gaps in their understanding of the guidelines for diet and PA. Participants agreed that personalized feedback would promote health-enhancing habits by enhancing confidence and motivation.

The focus groups and interview data were reviewed for 3 intervention functions expected to mediate a behavior change, for example, education, modeling behavior, and persuasive communication.

1. Education (to increase knowledge on how to identify EDNP food and on PA guidelines)

2. Modeling behavior (annotating food and beverage images by feedback on intake)

3. Persuasive communication (images and motivation enhancement using positive reinforcement in tailored communications) 
Table 3. Understanding user perspectives and experiences of participants on the clinical aims using the mobile food record app and their experiences or views about using a physical activity monitor.

\begin{tabular}{ll}
\hline Clinical aims and examples of questions or activity & Participant quotes \\
\hline Self-monitor diet & "It's really intuitive and easy; better than the apps where you need to find the food" \\
Practice using the mobile food record app & "I wouldn't use it if I was at the club with the guys. I wouldn't use it at work (nurse)" \\
How easy/difficult would it be to use to capture all your
\end{tabular}

food and drink for 4 days?

\section{Self-monitor physical activity}

Have you ever used an activity tracker? Prompt for wearable device, pedometer, mobile app

Any advice or support that helped?

"I used to use a watch that tracked steps and heart rate, it was good at first then all the alerts got annoying"

"Yeah it's good to see that you've done like ten thousand steps in a day"

\section{Increase fruit and vegetable consumption}

How much fruit and vegetables are recommended each day?

What advice would you give this person to help them lose weight? (Shown example meal)

What type of feedback could we send to help this person to get them to eat more vegetables?

What sort of things might get in the way?

"2 fruit and 5 veg but I'm not sure if it has to be 5 different types"

"your vegetables are supposed to be half your plate so many people don't know that" "If someone sends you a picture, send it back saying 'that's at least one serve of your five today"”

"No one eats that much veg, it's impossible"

\section{Reduce EDNP ${ }^{\mathrm{a}}$}

What advice would you give this person, to help them lose weight?

What sort of things might get in the way?

"because you've eaten this you have to run ten kilometers to work it off, sort of thing"

“...you go to Bunnings (national hardware chain with fundraising barbecues) you're going to get your sausage, there's no other options"

\section{Reduce intake of alcohol}

What advice would you give this person, to help them lose weight?

What sort of things might get in the way?

"Would be much better if he switched to a lighter beer, like only $4 \% "$

"If you're out, say watching sport in the afternoon, everyone else is drinking it would be hard to have water"

\section{Increase active minutes/decrease sedentary behavior}

How much physical activity is recommended each day?

"The adverts tell you half an hour a day and ten thousand steps. You can't do ten thousand steps in half an hour, it doesn't make sense"

Any ideas of how we could support them to do this?

"Show it like your bank account where you can track it and see where it's going"

What might make it easier/difficult?

"It needs to be friendly and informative and helpful"

${ }^{a}$ EDNP: energy-dense nutrient-poor.

Table 4 summarizes the stages of applying COM-B to the focus groups and interview data to identify nutrition, PA, and weight management intervention functions and features.

New ideas from participants were explored for feasibility and consistency with evidence-based diet and PA guidelines [42,43]. Rejected ideas included individual assessment of vitamin and mineral status and details on how much weight could be lost with a specific number of steps, as this was not consistent with evidence-based advice. Accepted ideas were the inclusion of participant food and beverage images from the mFR into the tailored dietary feedback. For PA, accepted ideas included using graphs for self-comparison of PA levels throughout the study, positive re-enforcement to acknowledge improvements in activity, and regular goal setting. There was a strong preference for visual feedback for both diet and PA. This was not feasible with text messages; therefore, feedback was primarily provided by email. Digital intervention features may continue to develop during the intervention and include aspects that were not originally mapped in this development phase [40]. 
Table 4. Summary of stages of applying capability, opportunity, motivation, and behavior framework to the focus groups and interview data to identify nutrition, physical activity, and weight management intervention functions and features.

\begin{tabular}{|c|c|c|c|}
\hline$C O M-B^{a}$ and themes & User preferences & Intervention functions & Intervention features \\
\hline \multicolumn{4}{|l|}{ Capability: psychological } \\
\hline Misinformation & $\begin{array}{l}\text { Simple expert advice; links to further } \\
\text { information }\end{array}$ & $\begin{array}{l}\text { Education; tailored feedback on perfor- } \\
\text { mance }\end{array}$ & Mobile food record; dietary goals \\
\hline \multicolumn{4}{|l|}{ Capability: physical } \\
\hline Environmental support & $\begin{array}{l}\text { Dietary self-monitoring tools is easy, } \\
\text { quick, and subtle }\end{array}$ & $\begin{array}{l}\text { Training: how to use the mobile food } \\
\text { record app }\end{array}$ & Mobile food record \\
\hline Environmental support & $\begin{array}{l}\text { PA monitor is easy to use and is visual- } \\
\text { ly appealing }\end{array}$ & Training: how to use the Fitbit charge 2 & $\begin{array}{l}\text { Fitbit Charge 2; tailored movement } \\
\text { goals }\end{array}$ \\
\hline \multicolumn{4}{|l|}{ Opportunity: physical } \\
\hline Environmental support & $\begin{array}{l}\text { Feedback provides visual information, } \\
\text { basis their food choice }\end{array}$ & $\begin{array}{l}\text { Education: link to Australian guidelines } \\
\text { for diet and } \mathrm{PA}^{\mathrm{b}}\end{array}$ & Tailored dietary feedback \\
\hline \multicolumn{4}{|l|}{ Opportunity: social } \\
\hline Social norms & $\begin{array}{l}\text { Feedback is nonjudgmental, supportive } \\
\text { tone }\end{array}$ & Supportive and friendly tone & $\begin{array}{l}\text { Tailored feedback, tailored educa- } \\
\text { tion }\end{array}$ \\
\hline \multicolumn{4}{|l|}{ Motivation } \\
\hline Confidence & $\begin{array}{l}\text { Goals for diet, PA, and weight change } \\
\text { are realistic goals }\end{array}$ & $\begin{array}{l}\text { Modelling; personalized examples of } \\
\text { how to improve their current behavior }\end{array}$ & $\begin{array}{l}\text { Tailored feedback; Fitbit Charge } \\
\text { 2; tailored movement goals }\end{array}$ \\
\hline
\end{tabular}

${ }^{\mathrm{a} C O M}-\mathrm{B}$ : capability, opportunity, motivation, and behavior.

${ }^{\mathrm{b}} \mathrm{PA}$ : physical activity.

\section{Discussion}

\section{Principal Findings}

This study reveals a lack of knowledge and confidence about evidence-based weight management behaviors and susceptibility to misinformation about nutrition. The results also suggest that the BCTs of self-monitoring and feedback on performance are well suited to this group. This paper follows previous examples of combining theory and the experience of users and experts to develop digital interventions [47]. Our findings explored factors affecting weight management behavior, all of which could be mapped to the COM-B model. Participants expressed concerns about their capability; misinformation and opportunities; availability of alternatives and motivation or plans to change their behavior $[45,47]$.

The capability theme was most notable, with lack of knowledge and misinformation being most prevalent. Despite awareness and positive attitudes toward the LiveLighter campaign, participants were still unaware of how to implement the messages from the campaign into their own lives. Several researchers have identified this as nutrition literacy, the ability to interpret and use nutrition information [65-67]. Misinformation about effective dietary strategies to manage their weight was evident; the energy content of alcohol was underestimated and potatoes were described as fattening. This highlights the need for more tailored and specific information that addresses participants' ability to understand and implement new behaviors. A recent review recommends interventions provide actionable feedback and information on where and when to perform the new behavior [68]. For example, using the mFR to assess a meal image (Figure 1) and then providing actionable feedback such as identifying sources of EDNP foods and providing suggestions for change.

Motivation to change eating habits and reduce alcohol intake was hindered by beliefs, and government guidelines on alcohol were considered unrealistic, a view found previously [69]. Similarly, participants were aware of the recommendations to eat 2 serves of fruit and 5 serves of vegetables, but did not believe this was necessary [70]. This seems to be compounded by limited or inaccurate knowledge of serving sizes and energy content of foods [71].

Ambivalence appeared to be a strong theme, with participants describing their competing desires. Although most participants admitted to actively try to restrict their intake of junk food, they also revealed that junk foods were associated with happiness and time off. Similarly, eating out was viewed as a major barrier to weight management because of excess portion sizes and lack of healthy options. However, it was also described as a compulsory, normal part of our culture. These views are supported by a previous study, which highlighted that people felt pressured to eat junk food to participate socially and avoid criticism from their peers [72]. In addition, behavioral science has identified that our habits are the salient drivers of behavior, rather than motivation or intention to change [73]. This suggests that interventions should focus on developing habitual changes and creating healthy options as the default choice [73].

Social factors appear to be both motivators and barriers to healthy eating. Although most people agree that eating a healthy diet is what should be done, the social context of eating was associated with alcohol and junk food. Qualitative studies with Australian men aged 18 to 25 years reported that healthy eating was seen as incongruent with the masculine stereotype [44]. 
Our study confirmed that this view also exists among older men and women.

\section{Strengths and Limitations}

A major strength of the study was the large sample of participants living with overweight and obesity and the inclusion of male and female participants. Although men are more likely to have a poor diet, carry excess weight, and experience weight-related disease, they are underrepresented in weight loss interventions. As a result, this study sought to recruit male participants to ensure that their views and preferences were represented in the development of the intervention. The transcripts were coded by gender. However, no apparent differences in preferences or views were found between men and women. Further studies with this cohort would benefit from exploring specific gender differences in the experience of weight loss behaviors and gender preferences for digital intervention features.

This research explored digital technology on several platforms, including the mFR app, wearable PA trackers, email, and text messaging. This made it difficult to apply a single framework exclusively for each of these elements to the intervention. As a result, Australian guidelines for weight management, diet, and physical activity informed target behaviors, rather than a theory-based process such as the behavior change wheel, intervention mapping, or the Integrate Design Assess and Share framework $[45,74,75]$.

The use of self-reported height and weight measures was a limitation of the study and may have led to inaccuracies in the reported BMI. At screening, volunteers were excluded if their BMI was <25. However, when asked at the focus groups to self-report their height and weight, 10 participants reported a BMI of $<25$. Therefore, the views expressed in these focus groups may not entirely reflect those living with overweight and obesity. Study participants primarily registered on the web via the LiveLighter website and were likely to already have an interest in digital weight management. Their preferences may differ from those who have not previously attempted to seek weight loss information online.

A limitation of the study is that the predetermined intention to develop a scalable digital behavior change intervention could have likely restricted the themes that emerged from the data. The purpose of this focus group study was to explore which intervention features would be acceptable and feasible to assist participants' behavior change. The study explored potential barriers and benefits of using technology, rather than the wider context of the lived experience of participants in relation to their weight issues, such as social support. This is a limitation of the study, and further in-depth research is needed to explore this issue. The strength of this research is that it explored participants' opinions on a variety of relatively accessible technological devices to gauge their suitability for intervention. Theoretically, these PA trackers are effective and ideal for hard-to-reach groups. Although they provide objective feedback, little is known about users' experiences or preferences regarding the use of these tools for self-monitoring purposes. Another limitation was that the discussion regarding social support was limited to identifying the desired frequency of researcher contact. This script focused specifically on the supportive features of the intervention and did not explore other social support as they were outside the scope of the study. A further limitation was that the pace at which this intervention was developed and evaluated was protracted in comparison with commercial interventions [76]. Recent industry and academic partnerships have demonstrated the potential to produce high-quality digital interventions at a commercial pace [77].

\section{Future Directions}

Dichotomous thinking about food and activity can impede efforts to make healthy lifestyle changes [78]. A more flexible and nonjudgmental approach can lead to better behavior change and reduce dietary restraint when supporting the psychological well-being of participants [39,79]. This intervention aims to adopt this flexible and nonjudgmental tone. The effectiveness of these strategies will be evaluated in a randomized controlled trial and exit interviews. Future studies will assess the relationship between behavior change and intervention features, consistent with guidelines for developing digital health interventions [49].

\section{Conclusions}

The ToDAy study was developed using a person-centered approach and behavior change theory. Focus groups and interviews were undertaken to explore user capability, opportunity, and motivation to perform the targeted behaviors for weight loss. The study revealed a lack of knowledge, confidence, and susceptibility to misinformation about evidence-based weight management behaviors. The findings suggest that a digital weight management intervention using mobile food records and activity trackers to inform tailored feedback may be an acceptable, feasible, and engaging strategy.

\section{Acknowledgments}

The authors would like to thank all the participants who generously gave up their time to participate in this study and Anne Finch, Iain Stephen Pratt (Cancer Council WA), and Joel Howell for their role as cofacilitators. CS is a PhD student supported by an Australian Government Research Training Program Scholarship. Funding for the ToDAy study was provided by a Healthway Health Promotion Research Grant and the East Metropolitan Health Service. The mFR app is funded by National Institute of Health, National Cancer Institute (1U01CA130784-01), and National Institute of Health, National Institute of Diabetes and Digestive and Kidney Diseases (1R01-DK073711-01A1, 2R56DK073711-04). The sponsors had no role in the design of the study; in the collection, analyses, or interpretation of data; in the writing of the manuscript; and in the decision to publish the results. The term "LiveLighter" is a registered trademark. The LiveLighter campaign is funded by the Western Australian Department of Health and at the time of this study, delivered by the National Heart Foundation (WA Division), and currently delivered by Cancer Council Western Australia. 


\section{Conflicts of Interest}

None declared.

\section{Multimedia Appendix 1}

Script for interviews and focus groups.

[DOCX File, 15 KB-Multimedia Appendix 1]

\section{References}

1. Profiles of Health, Australia, 2011-13. Australian Bureau of Statistics, Australian Government. 2011. URL: http://www. abs.gov.au/ausstats/abs@.nsf/Lookup/by\%20Subject/4338.

0 2011-13 Main\%20Features Overweight\%20and\%20obesity 10007 [accessed 2018-11-14] [WebCite Cache ID 73un7bvI2]

2. Jaacks LM, Vandevijvere S, Pan A, McGowan CJ, Wallace C, Imamura F, et al. The obesity transition: stages of the global epidemic. Lancet Diabetes Endocrinol 2019 Mar;7(3):231-240 [FREE Full text] [doi: 10.1016/S2213-8587(19)30026-9] [Medline: $\underline{\text { 30704950] }}$

3. Australian Health Survey: Nutrition First Results - Foods and Nutrients, 2011-12. Australian Bureau of Statistics, Australian Government. 2011. URL: http://www.abs.gov.au/AUSSTATS/abs@.nsf/Lookup/4364.0.55.007Main+Features12011-12 [accessed 2018-11-14] [WebCite Cache ID 73uoVjWZb]

4. Morley B, Niven P, Dixon H, Swanson M, Szybiak M, Shilton T, et al. Population-based evaluation of the 'LiveLighter' healthy weight and lifestyle mass media campaign. Health Educ Res 2016 Apr;31(2):121-135 [FREE Full text] [doi: 10.1093/her/cyw009] [Medline: 26956039]

5. Rhodes RE, Pfaeffli LA. Mediators of physical activity behaviour change among adult non-clinical populations: a review update. Int J Behav Nutr Phys Act 2010 May 11;7:37 [FREE Full text] [doi: 10.1186/1479-5868-7-37] [Medline: 20459781]

6. Hruby A, Hu FB. The epidemiology of obesity: a big picture. Pharmacoeconomics 2015 Jul;33(7):673-689 [FREE Full text] [doi: 10.1007/s40273-014-0243-x] [Medline: 25471927]

7. Wakefield MA, Loken B, Hornik RC. Use of mass media campaigns to change health behaviour. Lancet 2010 Oct 9;376(9748):1261-1271 [FREE Full text] [doi: 10.1016/S0140-6736(10)60809-4] [Medline: 20933263]

8. LiveLighter. 2020. URL: https://livelighter.com.au/ [accessed 2018-08-29] [WebCite Cache ID 721f8bzFZ]

9. Morley B, Niven P, Dixon H, Swanson M, Szybiak M, Shilton T, et al. Association of the LiveLighter mass media campaign with consumption of sugar-sweetened beverages: cohort study. Health Promot J Austr 2019 Dec;30(Suppl 1):34-42 [FREE Full text] [doi: 10.1002/hpja.244] [Medline: 30903631]

10. Morley B, Niven PH, Dixon HG, Swanson MG, McAleese AB, Wakefield MA. Controlled cohort evaluation of the mass media campaign's impact on adults' reported consumption of sugar-sweetened beverages. BMJ Open 2018 Apr 25;8(4):e019574 [FREE Full text] [doi: 10.1136/bmjopen-2017-019574] [Medline: 29695387]

11. Browne J, MacDonald C, Egan M, Delbridge R, McAleese A, Morley B, et al. You wouldn't eat 16 teaspoons of sugar-so why drink it? Aboriginal and Torres Strait Islander responses to the LiveLighter sugary drink campaign. Health Promot J Austr 2019 Apr;30(2):212-218. [doi: 10.1002/hpja.196] [Medline: 30144362]

12. Kreuter MF, Wray RJ. Tailored and targeted health communication: strategies for enhancing information relevance. Am $\mathbf{J}$ Health Behav 2003;27(Suppl 3):S227-S232. [doi: 10.5993/ajhb.27.1.s3.6] [Medline: 14672383]

13. Brug J, Glanz K, van Assema P, Kok G, van Breukelen GJ. The impact of computer-tailored feedback and iterative feedback on fat, fruit, and vegetable intake. Health Educ Behav 1998 Aug;25(4):517-531. [doi: 10.1177/109019819802500409] [Medline: $\underline{9690108]}$

14. Ryan K, Dockray S, Linehan C. A systematic review of tailored eHealth interventions for weight loss. Digit Health 2019;5:2055207619826685 [FREE Full text] [doi: 10.1177/2055207619826685] [Medline: 30783535]

15. Hawkins RP, Kreuter M, Resnicow K, Fishbein M, Dijkstra A. Understanding tailoring in communicating about health. Health Educ Res 2008 Jun;23(3):454-466 [FREE Full text] [doi: 10.1093/her/cyn004] [Medline: 18349033]

16. Krebs P, Prochaska JO, Rossi JS. A meta-analysis of computer-tailored interventions for health behavior change. Prev Med 2010;51(3-4):214-221 [FREE Full text] [doi: 10.1016/j.ypmed.2010.06.004] [Medline: 20558196]

17. Lustria ML, Cortese J, Noar SM, Glueckauf RL. Computer-tailored health interventions delivered over the web: review and analysis of key components. Patient Educ Couns 2009 Feb;74(2):156-173. [doi: 10.1016/j.pec.2008.08.023] [Medline: $\underline{18947966]}$

18. Clinical Practice Guidelines for the Management of Overweight and Obesity. The National Health and Medical Research Council (NHMRC). URL: https://www.nhmrc.gov.au/about-us/publications/

clinical-practice-guidelines-management-overweight-and-obesity [accessed 2019-02-07] [WebCite Cache ID 760BJX4o0]

19. Pirotta S, Joham A, Hochberg L, Moran L, Lim S, Hindle A, et al. Strategies to reduce attrition in weight loss interventions: a systematic review and meta-analysis. Obes Rev 2019 Oct;20(10):1400-1412. [doi: 10.1111/obr.12914] [Medline: 31347759] 
20. Rollo M, Burrows T, Vincze LJ, Harvey J, Collins CE, Hutchesson MJ. Cost evaluation of providing evidence-based dietetic services for weight management in adults: in-person versus eHealth delivery. Nutr Diet 2018 Feb;75(1):35-43. [doi: 10.1111/1747-0080.12335] [Medline: 29411491]

21. Walthouwer MJL, Oenema A, Lechner L, de Vries H. Use and effectiveness of a video- and text-driven web-based computer-tailored intervention: randomized controlled trial. J Med Internet Res 2015 Sep 25;17(9):e222 [FREE Full text] [doi: 10.2196/jmir.4496] [Medline: 26408488]

22. Springvloet L, Lechner L, de Vries H, Candel MJ, Oenema A. Short- and medium-term efficacy of a web-based computer-tailored nutrition education intervention for adults including cognitive and environmental feedback: randomized controlled trial. J Med Internet Res 2015 Jan 19;17(1):e23 [FREE Full text] [doi: 10.2196/jmir.3837] [Medline: 25599828]

23. Yardley L, Morrison L, Bradbury K, Muller I. The person-based approach to intervention development: application to digital health-related behavior change interventions. J Med Internet Res 2015 Jan 30;17(1):e30 [FREE Full text] [doi: 10.2196/jmir.4055] [Medline: 25639757]

24. Samdal GB, Eide GE, Barth T, Williams G, Meland E. Effective behaviour change techniques for physical activity and healthy eating in overweight and obese adults; systematic review and meta-regression analyses. Int J Behav Nutr Phys Act 2017 Mar 28;14(1):42 [FREE Full text] [doi: 10.1186/s12966-017-0494-y] [Medline: 28351367]

25. Michie S, Abraham C, Whittington C, McAteer J, Gupta S. Effective techniques in healthy eating and physical activity interventions: a meta-regression. Health Psychol 2009 Nov;28(6):690-701. [doi: 10.1037/a0016136] [Medline: 19916637]

26. Burke LE, Wang J, Sevick MA. Self-monitoring in weight loss: a systematic review of the literature. J Am Diet Assoc 2011 Jan;111(1):92-102 [FREE Full text] [doi: 10.1016/j.jada.2010.10.008] [Medline: 21185970]

27. Painter SL, Ahmed R, Hill JO, Kushner RF, Lindquist R, Brunning S, et al. What Matters in Weight Loss? An In-Depth Analysis of Self-Monitoring. J Med Internet Res 2017 May 12;19(5):e160 [FREE Full text] [doi: 10.2196/jmir.7457] [Medline: 28500022]

28. Cleary M, Escott P, Horsfall J, Walter G, Jackson D. Qualitative research: the optimal scholarly means of understanding the patient experience. Issues Ment Health Nurs 2014 Nov;35(11):902-904. [doi: 10.3109/01612840.2014.965619] [Medline: 25353304]

29. Lewin S, Glenton C, Oxman AD. Use of qualitative methods alongside randomised controlled trials of complex healthcare interventions: methodological study. Br Med J 2009 Sep 10;339:b3496 [FREE Full text] [doi: 10.1136/bmj.b3496] [Medline: 19744976]

30. Lozano-Sufrategui L. 'Sorry mate, you're probably a bit too fat to be able to do any of these': men's experiences of weight stigma. Int J Men's Health 2016;15(1):4-23 [FREE Full text]

31. Pagoto SL, Schneider KL, Oleski JL, Luciani JM, Bodenlos JS, Whited MC. Male inclusion in randomized controlled trials of lifestyle weight loss interventions. Obesity (Silver Spring) 2012 Jun;20(6):1234-1239 [FREE Full text] [doi: 10.1038/oby.2011.140] [Medline: 21633403]

32. Donnachie C, Wyke S, Mutrie N, Hunt K. 'It's like a personal motivator that you carried around wi' you': utilising self-determination theory to understand men's experiences of using pedometers to increase physical activity in a weight management programme. Int J Behav Nutr Phys Act 2017 May 5;14(1):61 [FREE Full text] [doi: 10.1186/s12966-017-0505-z] [Medline: 28476118]

33. Quested E, Kwasnicka D, Thøgersen-Ntoumani C, Gucciardi DF, Kerr DA, Hunt K, et al. Protocol for a gender-sensitised weight loss and healthy living programme for overweight and obese men delivered in Australian football league settings (Aussie-FIT): a feasibility and pilot randomised controlled trial. BMJ Open 2018 Oct 17;8(10):e022663. [doi: 10.1136/bmjopen-2018-022663] [Medline: 30337315]

34. Robertson C, Archibald D, Avenell A, Douglas F, Hoddinott P, van Teijlingen E, et al. Systematic reviews of and integrated report on the quantitative, qualitative and economic evidence base for the management of obesity in men. Health Technol Assess 2014 May;18(35):v-vi, xxiii [FREE Full text] [doi: 10.3310/hta18350] [Medline: 24857516]

35. Halse RE, Shoneye CL, Pollard CM, Jancey J, Scott JA, Pratt IS, et al. Improving nutrition and activity behaviors using digital technology and tailored feedback: protocol for the LiveLighter tailored diet and activity (today) randomized controlled trial. JMIR Res Protoc 2019 Feb 25;8(2):e12782 [FREE Full text] [doi: 10.2196/12782] [Medline: 30801257]

36. Thomas DR. A general inductive approach for analyzing qualitative evaluation data. Am J Eval 2016 Jun 30;27(2):237-246. [doi: $10.1177 / 1098214005283748$ ]

37. Tong A, Sainsbury P, Craig J. Consolidated criteria for reporting qualitative research (COREQ): a 32-item checklist for interviews and focus groups. Int J Qual Health Care 2007 Dec;19(6):349-357. [doi: 10.1093/intqhc/mzm042] [Medline: 17872937]

38. Kerr DA, Harray AJ, Pollard CM, Dhaliwal SS, Delp EJ, Howat PA, et al. The connecting health and technology study: a 6-month randomized controlled trial to improve nutrition behaviours using a mobile food record and text messaging support in young adults. Int J Behav Nutr Phys Act 2016 Apr 21;13:52 [FREE Full text] [doi: 10.1186/s12966-016-0376-8] [Medline: 27098449]

39. Pollard CM, Howat PA, Pratt IS, Boushey CJ, Delp EJ, Kerr DA. Preferred tone of nutrition text messages for young adults: focus group testing. JMIR Mhealth Uhealth 2016 Jan 19;4(1):e1 [FREE Full text] [doi: 10.2196/mhealth.4764] [Medline: 26787115] 
40. Mohr DC, Schueller SM, Montague E, Burns MN, Rashidi P. The behavioral intervention technology model: an integrated conceptual and technological framework for eHealth and mHealth interventions. J Med Internet Res 2014 Jun 5;16(6):e146 [FREE Full text] [doi: 10.2196/jmir.3077] [Medline: 24905070]

41. Mohr DC, Cheung K, Schueller SM, Hendricks Brown C, Duan N. Continuous evaluation of evolving behavioral intervention technologies. Am J Prev Med 2013 Oct;45(4):517-523 [FREE Full text] [doi: 10.1016/j.amepre.2013.06.006] [Medline: 24050429]

42. Educator Guide. Eat for Health. 2013. URL: https://www.eatforhealth.gov.au/sites/default/files/files/the_guidelines/

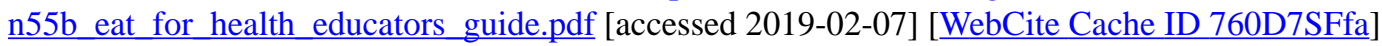

43. Australia's Physical Activity and Sedentary Behaviour Guidelines and the Australian 24-Hour Movement Guidelines. Australian Government Department of Health. 2017. URL: http://www.health.gov.au/internet/main/publishing.nsf/content/ health-pubhlth-strateg-phys-act-guidelines\#apaadult [accessed 2020-02-07] [WebCite Cache ID 760EH2cX9]

44. Ashton L, Morgan PJ, Hutchesson MJ, Rollo ME, Collins CE. Young men's preferences for design and delivery of physical activity and nutrition interventions: a mixed-methods study. Am J Mens Health 2017 Sep;11(5):1588-1599 [FREE Full text] [doi: 10.1177/1557988317714141] [Medline: 28675118]

45. Michie S, van Stralen MM, West R. The behaviour change wheel: a new method for characterising and designing behaviour change interventions. Implement Sci 2011 Apr 23;6:42 [FREE Full text] [doi: 10.1186/1748-5908-6-42] [Medline: 21513547]

46. Miller CL. Integrating Consumer Engagement in Health and Medical Research - An Australian Framework. Health Research Policy and Systems. 2017. URL: https://health-policy-systems.biomedcentral.com/articles/10.1186/s12961-017-0171-2 [accessed 2020-07-30]

47. Curtis KE, Lahiri S, Brown KE. Targeting parents for childhood weight management: development of a theory-driven and user-centered healthy eating app. JMIR Mhealth Uhealth 2015 Jun 18;3(2):e69 [FREE Full text] [doi: 10.2196/mhealth.3857] [Medline: 26088692]

48. White BK, Martin A, White JA, Burns SK, Maycock BR, Giglia RC, et al. Theory-based design and development of a socially connected, gamified mobile app for men about breastfeeding (milk man). JMIR Mhealth Uhealth 2016 Jun 27;4(2):e81 [FREE Full text] [doi: 10.2196/mhealth.5652] [Medline: 27349756]

49. Michie S, Yardley L, West R, Patrick K, Greaves F. Developing and evaluating digital interventions to promote behavior change in health and health care: recommendations resulting from an international workshop. J Med Internet Res 2017 Jun 29;19(6):e232 [FREE Full text] [doi: 10.2196/jmir.7126] [Medline: 28663162]

50. Craig P, Dieppe P, Macintyre S, Michie S, Nazareth I, Petticrew M, Medical Research Council Guidance. Developing and evaluating complex interventions: the new medical research council guidance. Br Med J 2008 Sep 29;337:a1655 [FREE Full text] [doi: 10.1136/bmj.a1655] [Medline: 18824488 ]

51. World Health Organization. Monitoring and Evaluating Digital Health Interventions: A Practical Guide to Conducting Research and Assessment. Geneva, Switzerland: World Health Organization; 2020.

52. Agarwal S, LeFevre AE, Lee J, L'Engle K, Mehl G, Sinha C, WHO mHealth Technical Evidence Review Group. Guidelines for reporting of health interventions using mobile phones: mobile health (mHealth) evidence reporting and assessment (mERA) checklist. Br Med J 2016 Mar 17;352:i1174. [doi: 10.1136/bmj.i1174] [Medline: 26988021]

53. Michie S, Richardson M, Johnston M, Abraham C, Francis J, Hardeman W, et al. The behavior change technique taxonomy (v1) of 93 hierarchically clustered techniques: building an international consensus for the reporting of behavior change interventions. Ann Behav Med 2013 Aug;46(1):81-95. [doi: 10.1007/s12160-013-9486-6] [Medline: 23512568]

54. Australian Alcohol Guidelines. The National Health and Medical Research Council (NHMRC). URL: https:/ /alcoholthinkagain.com.au/alcohol-your-health/online-tools/australian-alcohol-guidelines/

55. Palinkas LA, Horwitz SM, Green CA, Wisdom JP, Duan N, Hoagwood K. Purposeful sampling for qualitative data collection and analysis in mixed method implementation research. Adm Policy Ment Health 2015 Sep;42(5):533-544 [FREE Full text] [doi: 10.1007/s10488-013-0528-y] [Medline: 24193818]

56. Mummah SA, King AC, Gardner CD, Sutton S. Iterative development of vegethon: a theory-based mobile app intervention to increase vegetable consumption. Int J Behav Nutr Phys Act 2016 Aug 8;13:90 [FREE Full text] [doi:

10.1186/s12966-016-0400-z] [Medline: 27501724]

57. Boushey C, Spoden M, Delp E, Zhu F, Bosch M, Ahmad Z, et al. Reported energy intake accuracy compared to doubly labeled water and usability of the mobile food record among community dwelling adults. Nutrients 2017 Mar 22;9(3):312 [FREE Full text] [doi: 10.3390/nu9030312] [Medline: 28327502]

58. Ahmad Z, Kerr DA, Bosch M, Boushey CJ, Delp EJ, Khanna N, et al. A mobile food record for integrated dietary assessment. MADiMa16 (2016) 2016 Oct;2016:53-62 [FREE Full text] [doi: 10.1145/2986035.2986038] [Medline: 28691119]

59. Zhu F. An Image Analysis System for Dietary Assessment and Evaluation. In: IEEE International Conference on Image Processing. 2010 Presented at: ICIP'10; September 26-29, 2010; Hong Kong, China. [doi: 10.1109/icip.2010.5650848]

60. Shoneye C, Johnson F, Steptoe A, Wardle J. A qualitative analysis of black and white British women's attitudes to weight and weight control. J Hum Nutr Diet 2011 Dec;24(6):536-542. [doi: 10.1111/j.1365-277X.2011.01198.x] [Medline: 21838745]

61. Russell RD, Black LJ, Sherriff JL, Begley A. Dietary responses to a multiple sclerosis diagnosis: a qualitative study. Eur J Clin Nutr 2019 Apr;73(4):601-608. [doi: 10.1038/s41430-018-0252-5] [Medline: 29941913] 
62. Begley A, Ringrose K, Giglia R, Scott J. Mothers' understanding of infant feeding guidelines and their associated practices: a qualitative analysis. Int J Environ Res Public Health 2019 Mar 29;16(7):1141 [FREE Full text] [doi: 10.3390/ijerph16071141] [Medline: 30934967]

63. Braun V, Clarke V. Using thematic analysis in psychology. Qual Res Psychol 2006 Jan;3(2):77-101. [doi: 10.1191/1478088706qp063oa]

64. Braun V, Victoria C, Nikki H, Gareth T. Thematic analysis. Res Method Health Soc Sci 2020;-:843-860. [doi: 10.1007/978-981-10-5251-4_103]

65. Velardo S. The nuances of health literacy, nutrition literacy, and food literacy. J Nutr Educ Behav 2015;47(4):385-9.e1. [doi: 10.1016/j.jneb.2015.04.328] [Medline: 26026651]

66. Silk KJ, Sherry J, Winn B, Keesecker N, Horodynski MA, Sayir A. Increasing nutrition literacy: testing the effectiveness of print, web site, and game modalities. J Nutr Educ Behav 2008;40(1):3-10. [doi: 10.1016/j.jneb.2007.08.012] [Medline: $\underline{18174098]}$

67. Gibbs H, Chapman-Novakofski K. Exploring nutrition literacy: attention to assessment and the skills clients need. Health 2012;4(3):120-124. [doi: 10.4236/health.2012.43019]

68. Schembre SM, Liao Y, Robertson MC, Dunton GF, Kerr J, Haffey ME, et al. Just-in-time feedback in diet and physical activity interventions: systematic review and practical design framework. J Med Internet Res 2018 Mar 22;20(3):e106 [FREE Full text] [doi: 10.2196/jmir.8701] [Medline: 29567638]

69. Harrison L, Kelly P, Lindsay J, Advocat J, Hickey C. 'I don't know anyone that has two drinks a day': young people, alcohol and the government of pleasure. Health, Risk \& Society 2011 Aug;13(5):469-486. [doi: 10.1080/13698575.2011.596190]

70. Carter OB, Pollard CM, Atkins JF, Marie Milliner J, Pratt IS. 'We're not told why--we're just told': qualitative reflections about the Western Australian Go for 2\&5 fruit and vegetable campaign. Public Health Nutr 2011 Jun;14(6):982-988. [doi: 10.1017/S1368980010003381] [Medline: 21205404]

71. Kothe E, Mullan B. Perceptions of fruit and vegetable dietary guidelines among Australian young adults. Nutr Dietetics 2011;68(4):262-266. [doi: 10.1111/j.1747-0080.2011.01550.x]

72. Brantley PJ, Stewart DW, Myers VH, Matthews-Ewald MR, Ard JD, Coughlin JW, et al. Psychosocial predictors of weight regain in the weight loss maintenance trial. J Behav Med 2014 Dec;37(6):1155-1168 [FREE Full text] [doi: 10.1007/s10865-014-9565-6] [Medline: 24722826]

73. Mullan B, Novoradovskaya E. Habit mechanisms and behavioural complexity. In: The Psychology of Habit. New York, USA: Springer; 2018.

74. Mummah SA, Robinson TN, King AC, Gardner CD, Sutton S. IDEAS (integrate, design, assess, and share): a framework and toolkit of strategies for the development of more effective digital interventions to change health behavior. J Med Internet Res 2016 Dec 16;18(12):e317 [FREE Full text] [doi: 10.2196/jmir.5927] [Medline: 27986647]

75. Brendryen H, Johansen A, Nesvåg S, Kok G, Duckert F. Constructing a theory- and evidence-based treatment rationale for complex ehealth interventions: development of an online alcohol intervention using an intervention mapping approach. JMIR Res Protoc 2013 Jan 23;2(1):e6 [FREE Full text] [doi: 10.2196/resprot.2371] [Medline: 23612478]

76. Riley WT, Rivera DE, Atienza AA, Nilsen W, Allison SM, Mermelstein R. Health behavior models in the age of mobile interventions: are our theories up to the task? Transl Behav Med 2011 Mar;1(1):53-71 [FREE Full text] [doi: 10.1007/s13142-011-0021-7] [Medline: 21796270]

77. Hendrie GA, James-Martin G, Williams G, Brindal E, Whyte B, Crook A. The development of vegeze: smartphone app to increase vegetable consumption in Australian adults. JMIR Form Res 2019 Mar 27;3(1):e10731 [FREE Full text] [doi: 10.2196/10731] [Medline: $\underline{30916653}$ ]

78. Palascha A, van Kleef E, van Trijp HC. How does thinking in Black and White terms relate to eating behavior and weight regain? J Health Psychol 2015 May;20(5):638-648. [doi: 10.1177/1359105315573440] [Medline: 25903250]

79. Sairanen E, Lappalainen R, Lapveteläinen A, Tolvanen A, Karhunen L. Flexibility in weight management. Eat Behav 2014 Apr;15(2):218-224. [doi: 10.1016/j.eatbeh.2014.01.008] [Medline: 24854807]

\section{Abbreviations}

BCT: behavior change technique

BIT: behavioral intervention technology

COM-B: capability, opportunity, motivation, and behavior framework

EDNP: energy-dense nutrient-poor

ToDAy: Tailored Diet and Activity

PA: physical activity

SSB: sugar-sweetened beverage 
Edited by G Eysenbach; submitted 30.01.20; peer-reviewed by L Goff, C Valle, A Videira-Silva; comments to author 10.04.20; revised version received 15.06.20; accepted 07.07.20; published 09.09.20

Please cite as:

Shoneye CL, Mullan B, Begley A, Pollard CM, Jancey J, Kerr DA

Design and Development of a Digital Weight Management Intervention (ToDAy): Qualitative Study

JMIR Mhealth Uhealth 2020;8(9):e17919

URL: https://mhealth.jmir.org/2020/9/e17919

doi: 10.2196/17919

PMID: 32641284

(C) Charlene L Shoneye, Barbara Mullan, Andrea Begley, Christina M Pollard, Jonine Jancey, Deborah A Kerr. Originally published in JMIR mHealth and uHealth (http://mhealth.jmir.org), 09.09.2020. This is an open-access article distributed under the terms of the Creative Commons Attribution License (https://creativecommons.org/licenses/by/4.0/), which permits unrestricted use, distribution, and reproduction in any medium, provided the original work, first published in JMIR mHealth and uHealth, is properly cited. The complete bibliographic information, a link to the original publication on http://mhealth.jmir.org/, as well as this copyright and license information must be included. 